\title{
Changing Gender Roles And Personality Development
}

\author{
Asma Manzoor \\ \& \\ Saba Imran Ali \\ Women's Studies \\ University of Karachi
}

\begin{abstract}
Despite the many differences among individuals, there are certain basic commonalities in our lives, of which the most obvious is that we are living beings: we are born, we grow, and eventually we die. This much, we all share and we all know it. This study examines theoretical construct of gender roles in the context of social and behavioral norms. This paper also discusses the development of one's personality. Based on a combination of the opinions of experts and observations, the paper contends that all human personality development is variable and different. The paper also claims that personality development springs from complicated interactions of 'nature' and 'nurture' plus outside environmental characteristics, such as social and cultural expectations, peer group interactions and the influences of teachers and other relatives.
\end{abstract}

تلخيص المقال - - ال

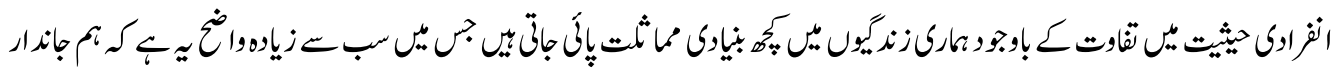

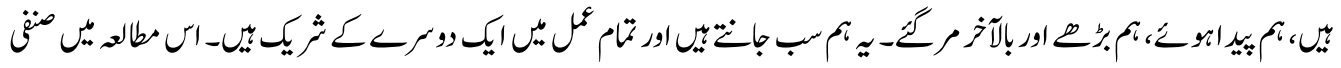

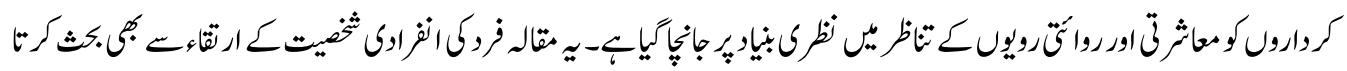

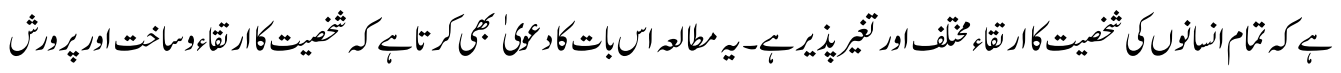

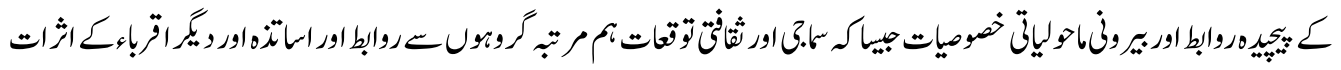

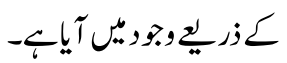

\section{Introduction}

A 'gender role' is a theoretical construct in the social sciences and humanities that refers to a set of social and behavioral norms that, within a specific culture, are widely considered to be socially appropriate for individuals of a specific gender. Proponents of gender role theory assert that observed gender differences in behavior and personality characteristics are, at least in part, socially constructed, and therefore, the product of socialization experiences; this contrasts with other models of gender that assert that gender differences are "essential" to biological sex. Different researches supports this theory, finding gender differences in almost all societies, but with differences in the 
norms adopted, suggesting that gender differences are, at least partly, influenced by culture (Connell, 1987).

Gender has several valid definitions but here it refers to an individual's inner sex or psychological sense of being a male or female irrespective of one's (outer) sex identity as determined by one's sexual organs. There are two main genders: masculine (male), or feminine (female). Gender identity refers to the options available to members of a society to choose from a set of social identities, based on the combination of one's sex identity on the one hand, and one's natural gender, interests and social experiences on the other. Some ancient tribes have more than five human genders. Some non-Western societies have three human genders -man, woman and third gender. Gender roles refer to the set of attitudes and behaviors socially expected from the members of a particular gender identity. Gender roles, unlike natural human genders, are socially constructed. They may reflect natural gender aspirations of the members of that gender identity, or they may be politicised and manipulated, which then result in the oppression of people (Connell, 1987).

The concrete behavior of individuals is a consequence of both socially enforced rules and values, and individual disposition, whether genetic, unconscious, or conscious. Some researchers emphasize the objective social system and others emphasize subjective orientations and dispositions. Creativity may cause the rules and values to change over time. Cultures and societies are dynamic and ever-changing, but there has been extensive debate as to how, and how fast, they may change. Such debates are especially contentious when they involve the gender/sex system, as people have widely differing views about how much gender depends on biological sex (DuBay, 1987).

A person's gender role is composed of several elements and can be expressed through clothing, behaviour, choice of work, personal relationships and other factors. These elements are not concrete and have evolved through time. Traditionally only feminine and masculine gender roles existed, however, over time many different acceptable male or female gender roles have emerged. An individual can either identify themselves with a subculture or social group which results in them having diverse gender roles. Historically, for example, eunuchs had a different gender role because their biology was changed (Brockhaus, 2001).

\section{Talcott Parson's View of Gender Roles}

Talcott Parson's developed a model of the nuclear family in 1955. (At that place and time, the nuclear family was the prevalent family structure.) It compared a strictly traditional view of gender roles (from an industrial-age American perspective) to a more liberal view. 
The Parsons model was used to contrast and illustrate extreme positions on gender roles. Model A describes total separation of male and female roles, while Model B describes the complete dissolution between gender roles (Parsons, 1955).

\begin{tabular}{|l|l|l|}
\hline & Model A - Total role segregation & Model B - Total integration of roles \\
\hline Education & $\begin{array}{l}\text { Gender-specific education; high professional } \\
\text { qualification is important only for the man }\end{array}$ & $\begin{array}{l}\text { Co-educative schools, same content of } \\
\text { classes for girls and boys, same } \\
\text { qualification for men and women. }\end{array}$ \\
\hline Profession & $\begin{array}{l}\text { The workplace is not the primary area of } \\
\text { women; career and professional advancement } \\
\text { is deemed unimportant for women }\end{array}$ & $\begin{array}{l}\text { For women, career is just as important as } \\
\text { for men; Therefore equal professional } \\
\text { opportunities for men and women are } \\
\text { necessary. }\end{array}$ \\
\hline Housework & $\begin{array}{l}\text { Housekeeping and child care are the primary } \\
\text { functions of the woman; participation of the } \\
\text { man in these functions is only partially wanted. }\end{array}$ & $\begin{array}{l}\text { All housework is done by both parties to } \\
\text { the marriage in equal shares. }\end{array}$ \\
\hline $\begin{array}{l}\text { Decision } \\
\text { making }\end{array}$ & $\begin{array}{l}\text { In case of conflict, man has the last say, for } \\
\text { example in choosing the place to live, choice } \\
\text { of school for children, buying decisions }\end{array}$ & $\begin{array}{l}\text { Neither partner dominates; solutions do } \\
\text { not always follow the principle of finding } \\
\text { a concerted decision; } \text { status quo is } \\
\text { maintained if disagreement occurs. }\end{array}$ \\
\hline $\begin{array}{l}\text { Child care and } \\
\text { education }\end{array}$ & $\begin{array}{l}\text { Woman takes care of the largest part of these } \\
\text { functions; she educates children and cares for } \\
\text { them in every way }\end{array}$ & $\begin{array}{l}\text { Man and woman share these functions } \\
\text { equally. }\end{array}$ \\
\hline
\end{tabular}

Source: Family Socialization and Interaction Process (Parsons, 1955).

However, these extreme positions are rarely found in reality; actual behavior of individuals is usually somewhere between these poles. The most common 'model' followed in real life in the United States and Britain is the 'model of double burden'

According to the interactionist approach, roles (including gender roles) are not fixed, but are constantly negotiated between individuals. In North America and southern South America, this is the most common approach among families whose business is agriculture.

Gender roles can influence all kinds of behaviors, such as choice of clothing, choice of work and personal relationships; e.g., parental status (Parsons, 1955). 


\section{Personality}

Personality usually refers to something that a person has, does, or is; it is attached to a specific person. We do not refer to personality apart from people. When we attribute personality to other entities, like groups, nations, animals, or machines, we imply that these entities are like people, not that people are like them. Personality is also usually brought to a situation and taken away from it. When we speak of personality, we mean a quality that transcends the momentary demands and pressures of a particular time and place. As we have seen, personality is rarely used to describe the material attributes, possessions, and status of a person. Personality usually refers to a person, to his or her behaviour - thoughts, actions, and feelings. Accordingly, personality is the province of psychologist, not the biologist, the economist or the historian (Peterson, 1988).

Not every aspect of a person's psychological makeup is typically classified as personality. Most uses of personality point to general properties of a person. And it usually refers to pervasive properties of an individual, those evident in a variety of domains. Personality is not how you can cut your toenails, unless that is also how you cut your fingernails, trim your moustache, mow your lawn, trim your steak, cut your losses, sever your romances, and purge your computer files. In this sense, personality describes the whole person, not just the fine print. Psychologists sometimes call the study of personality the field of individual differences, meaning the ways in which people differ from each other (Peterson, 1988).

Haviland defines personality as "the distinctive way a person thinks, feels, and behaves," and is shaped by many factors that circulate in a person's environment. What a person learns, how they learn it, early childhood experiences, and dependence training vs. independence training, all plot points on the person's cognitive map and outlines the basis for their personality. The development of a strong and healthy personality is vital to a person's sense of belonging, worth, and self. If negative experiences overwhelm the cognitive map, the person may develop

personality disorders or mood disorders that impede their ability to function in society (Haviland, 2002).

\section{Anthropological Contributions to the Understanding of Personality Development}

As mentioned earlier personality is "the distinctive way a person thinks, feels, and behaves" (Haviland, 2002). Even though there are similarities in generalized personality traits, each person has their own unique personality. The uniqueness of personality derives from the unique circumstances and elements that shape the development of personality. Anthropologist have studied the issue of personality development and have ruled that gender differences caused by biological factors vary 
from culture to culture, and depend a great deal the economy of the culture and the way in which they are raised (Haviland, 2002)

\section{Approaches to Personality Development}

As time went on, ideas about the differences between men and women were formalized into the identification of women as not only different but lesser. For example, Plato described women as weaker and inferior. Aristotle more specifically depicted women as incomplete and incompetent because of their inability to produce semen. Together with the conception of a women a deficient man was the view of women as possessing frail personalities - emotional, unprincipled, suggestible, and indecisive. In the Hebrew, and later the Christian Bible, men not only wielded te power but also held the higher moral authority, although women occasionally played important roles. The view of females as incomplete or imperfect males persisted for centuries, and Thomas Aquinas perpetuated this idea, providing a religious rationale for the inferiority of women. As we see, under Darwin's influence, the functional school of psychology declared that behavior and thought evolve as a result of their functionality for survival. For example, proponents emphasized the issue of maternal instinct, which was defined as "an inborn emotional tendency toward nurturance that was triggered by contact with a helpless infant". The functionalists viewed women's so-called maternal instinct as central to their lives, precluding their development of other pursuits. These theorists also explained that the maternal instinct revealed itself in other domains where women nurtured others, such as in their relationships with their spouses and close friends. These concepts were used to both explain and justify the dominant position of men and submissive position of women in the contemporary society. As we have seen throughout in this article, many ideas about personality are inextricably bound up with the biases of society. More modern psychological theories of gender development have used the various modern perspectives, looking for cultural, socialization, cognitive, and social learning explanations of gender differences in personality, in addition to recognizing physiological influences. Some theories postulate an interaction of biological and environmental factors that produces the traits we think of as masculine and feminine (Friedman,1999).

The assumptions we make about differences between man and women, and their causes, may lead to various important consequences. For example, if gender differences are seen to be primarily psychologically and biologically determined, the they will tend to be considered permanent, unchangeable, and even morally correct. If these differences are seen as learned through reinforcement, they can probably be more readily changed. If they are seen as basic and large rather than as changing and overlapping, then different social roles will be assigned to men and women, and so on. 
The Eight Basic Aspects of Personality

\begin{tabular}{|c|c|}
\hline Perspective & Key Strength \\
\hline Psychoanalytic & $\begin{array}{l}\text { Attention to unconscious influences; importance of sexual drives even in nonsexual } \\
\text { spheres }\end{array}$ \\
\hline Ego & $\begin{array}{l}\text { Emphasis on the self as it struggles to cope with emotions and drives on the inside } \\
\text { and the demands of others on the outside. }\end{array}$ \\
\hline Biological & $\begin{array}{l}\text { Focuses on tendencies and limits imposed by biological inheritance; can be easily } \\
\text { combined with most other approaches. }\end{array}$ \\
\hline Behaviorist & $\begin{array}{l}\text { Can force a more scientific analysis of the learning experiences that shape } \\
\text { personality. }\end{array}$ \\
\hline Cognitive & $\begin{array}{l}\text { Captures active nature of human thought; uses modern knowledge from cognitive } \\
\text { psychology. }\end{array}$ \\
\hline Trait & Good individual assessment techniques. \\
\hline Humanistic & $\begin{array}{l}\text { Appreciates the spiritual nature of a person; emphasizes struggles for self- } \\
\text { fulfillment and dignity. }\end{array}$ \\
\hline Interactionist & Understand that we are different selves in different situations. \\
\hline
\end{tabular}

Source: (Friedman,1999).

The idea that individuals have distinctive personalities has a long history--for example, five hundred years ago, Shakespeare made references to temperament in his plays, and the concept was old even then. Today, most of us accept the idea that individuals show some consistency in behavior over time and across situations, and we describe this consistency as representing the individual's "personality". Indeed, social psychologist George Kelley once commented that "in everyday life, we are all personality theorists"! As obvious as the idea seems, however, the study of personality is not without controversy. In fact, psychologists of different approaches have very different views of what produces the behavioral consistency we call personality--or even whether it really exists (Perspective on Development, 2010).

Not surprisingly, psychologists favoring the Biological approach tend to see personality as based on hereditary processes. In the past century, a model of personality based on body shape was developed by William Sheldon, who argued that body type was closely related to 'temperament', and therefore personality. Sheldon's model, like many personality theories which seek to categorize people into a limited number of types, tended to oversimplify differences among individuals, and is generally regarded by most psychologists as invalid (Arraj,1996). However, in the past decade, there has been a resurgence of interest in the role 
of temperament as a factor in personality, and a variety of studies, by Stella Chess, Jerome Kagan, and others, have provided new understanding of temperament as an innate characteristic.

By contrast, Behaviorists have questioned whether personality is anything more than an imaginary construct. Since Behaviorists see individual differences as the product of prior learning, consistency (if it occurs at all in behavior) would simply reflect that the environment is relatively consistent.

Similarly, Cognitive psychologists like Walter Mischel have questioned the notion that personality reflects any innate process; instead, Mischel and similar theorists focus on a combination of mental schemata and environmental influences. The idea that mental schemata influence behaviors can be traced back to the pioneering work of Jean Piaget, who believed that basic cognitive processes of 'assimilation and accommodation' underlie all of our interactions with the world. More recently, theorists like Lawrence Kohlberg have extended the idea of cognitive structures to areas like moral development (Perspective on Development, 2010).

Psychodynamic theorists of course see behavior in terms of the processes that motivate our behavior. From this point of view, personality develops out of the interaction of basic drives and environmental experience. Freud's theory is certainly the best known psychodynamic theory, but other models build on a similar interaction of mental processes and environmental influences.

The Humanistic Approach emphasizes healthy growth, and argues that other approaches (notably the Psychodynamic) fail because they offer no clear description of what it means to develop in a healthy way. Curiously, though, the primary Humanistic theories provide little detail about the process of growth. As the text discusses, Rogers favors a process orientation, rather than suggesting there are discrete stages of development, but in the end the Humanistic Approach is less than satisfying as a model for understanding the details of development (Perspective on Development, 2010).

\section{Gender Role Development}

Gender-role development is one of the most important areas of human development. In fact, the sex of a newborn sets the agenda for a whole array of developmental experiences that will influence the person throughout his or her life. When a baby is born, the parents announce either "It's a boy!" or "It's a girl!" and most parents try to dress their baby so that its sex is obvious. From the very moment of birth, boys and girls are treated differently (Friedman,1999). The years from about age two to age six are crucial years in the development of gender roles. It is during 
these years that children become aware of their gender, where play styles and behaviors begin to crystallize around that core identity of "I am a girl" or "I am a boy. Because of the centrality of gender-role development during these years, most theories of social and personality development highlight the early childhood years. For example, in the psychoanalytic theory of Sigmund Freud, in the third stage of psychosexual development a male child encounters the Oedipal Crisis, a time when the only way in which he can cope with his desire for his mother and fear of his father is to completely identify and incorporate his father's characteristics within himself. Freud posited a similar process for girls' desires for their fathers (the Electra complex). Although many contemporary psychologists do not agree with this theory in general, Freud is credited with highlighting the development of gender and gender-role behaviors very early in childhood and their link to identification with parents (Erikson, 1968).

The often controversial study of the development of gender is a topic that is inherently interesting to parents, students, researchers, and scholars for several reasons. First and foremost, one's sex is one of the most salient characteristics that is presented to other people. Second, who one is as a male or a female becomes a significant part of one's overall identity; it is one of the first descriptors people use about themselves. Labeling oneself as a "boy" or "girl" can begin as early as age eighteen months. Third, gender is an important mediator of human experiences and the way in which individuals interact with each other and the physical environment. Individuals' choices of friends, toys, classes taken in middle school, and vocation all are influenced by sex. Finally, the study of sex, gender development, and sex differences becomes the focal point of an age-old controversy that has influenced the field of developmental psychology: the naturenurture controversy. Are gender roles and sex differences biologically determined? What are the effects of society and culture on gender and sex? How do biology (nature) and environment (nurture) interact and mutually influence each other in this significant dimension of human development? (Beal, 1994).

When discussing gender-role development, the definitions of the terms "sex" and "gender" need to be understood. Referring to the nature-nurture controversy, scholars have found it important to distinguish those aspects of males and females that can be attributed to biology and those that can be attributed to social influences. The term "sex" denotes the actual physical structure of individuals that define them as male or female. Sex is determined by genetic structure, internal reproductive organs, the organization of the brain (such as in the control of hormone production), and external genitalia. By contrast, the behavior of individuals as males or females, the types of roles they assume, and their personality characteristics, may be as much a function of social expectations and interactions as their biological makeup. For example, in American culture, females are expected to be nurturing, and males aggressive. These behaviors and characteristics are dependent upon the social context. In order to differentiate social roles and behaviors from 
biological features, scholars refer to these as "gender" and "gender roles." Obviously, sex and gender are intertwined. Social expectations usually are enacted once body parts reveal the biological makeup of the individual (Beal, 1994).

Both sex and gender have a developmental story to tell that begins before birth (prenatal) and continues throughout the lifespan. Important developmental changes occur from conception through the adolescence years, and there are important theoretical perspectives and research studies that have tried to shed light on these developmental accomplishments (Beal, 1994).

\section{Conclusion}

Each individual's personality is shaped by a unique set of circumstances and experiences. The way in which one learns about themselves and their world, and what they learn affects the way their personality develops, and determines if a positive or negative self-image will be created. Other factors that shape one's personality are the techniques used in one's upbringing. Dependence training encourages dependence and unity of a group, while independence training encourages self-reliance and striving for personal gain. The culture one grows up in also has influential power on personality development. Cultural model personalities define what is "normal" and "abnormal" within a society. It also helps to define sex roles, and social patterns.

\section{References}

Arraj, James \& Arraj, Jim (1996) The Mystery of Matter, Chilioquin, USA, Inner Growth Books.

Beal, Carole R. (1994) Boys and Girls: The Development of Gender Roles, New York, USA, McGraw-Hill.

Brockhaus (2001) Encyclopedia of Psychology. Connell, Robert William (1987) Gender and Power, Cambridge, UK, Cambridge University Press.

DuBay, William H. (1987) Gay Identity: The Self Under Ban, Jrfferson, NC, USA, McFarland \& Company.

Erikson, Erik H. (1968) Identity, Youth, and Crisis, New York, USA, Norton.

Friedman, Howard S. \& Schustack, Miriam W. (1999) Personality: Classic Theories and Modern Research, Boston, USA, Allyn and Bacon. 
Haviland, William A. (2002) Cultural Anthropology $\left(10^{\text {th }}\right.$ ed.). Fort Worth, USA, Harcourt College Publishers, p.129.

Parsons, Talcott (1955) Family Socialization and Interaction Process, New York, USA, Free Press.

Peterson, Christopher (1988) Personality, New York, USA, Harcourt Brace Jovanovich.

Perspective on Development, Retrieved on July 11, 2010 http://www.mcgrawhill.co.uk/openup/approach/ development.htm.

Asma Manzoor is Lecturer in the Centre of Excellence for Women's Studies, University of Karachi.

Saba Imran Ali is Lecturer in the Centre of Excellence for Women's Studies, University of Karachi. 